\title{
MAXIMAL BOOTSTRAP CURRENT TOKAMAK EQUILIBRIA IN THE FIRST STABILITY REGIME
}

\author{
by
}

David A. Ehst and Kenneth Evans, Jr.

\section{MASTER}

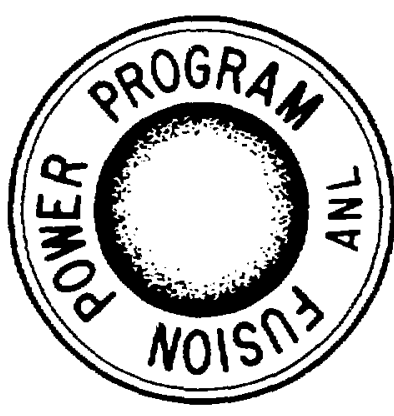

\section{FUSION POWER PROGRAM \\ Operated by}

Argonne National Laboratory 9700 South Cass Avenue Argonne, Illinois 60439

The University of Chicago for the U.S. Department of Energy under Contract W-31-109-Eng-38 
Argonne Naltional Laboralory, with facilities in the states of Illinois and Idaho, is owned by the United State's govemment, and operated by The Universily of Chicigo under the provisions of a contract with the Department of Energy.

\section{DISCLAIMER}

This report was prepared as an account of work sponsored by an agency of the United States Government. Neither the United States Government nor any agency thereof, nor iny of their employees, makes any warranty, express or implied, or assumes any legal liability or responsibility for the accuracy, completeness, or usefulness of any information. apparatus, product, or process disclosed. or represents that its use would not infringe privately owned rights. Reference herein to any specific commercial product, process, or service by trade name, trademark, manufaclurer, or otherwise. does not necessarily constitute or imply its endorsement, recommendation, or favoring by the United States Government or any agency thereof. The views and opinions of authors expressed herein do not necessarily state or reflect those of the United States Govermment or any agency thereof.

This report has been reproduced from the best available copy.

Available from the National Technical Information Service NTIS Energy Distribution Center

P.O. Box 1300

Oak Ridge, TN 37831

Price: Printed Copy A03

Microfiche AOl 


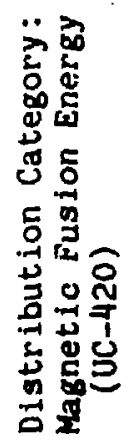

This report was prepared as an account of work sponeored by an agency of the United States Government. Neither the United States Government nor any agency thereof, nor any of their employees, makes any warranty, expreas or implied, or assumes any legal liability or responsibility for the accuracy, completeness, or usefulness of any information, apporatus, product, or process disclosed, or repreacents that its use would not infringe privately owned rights. Reference herein to any specific commercial product, process, or service by trade name, trademark, manufacturer, or otherwise doea not necesearily constitute or imply its endorsement, recommendation, or favoring by the United States Government or any arency thereof. The views and opinions of authors expresed herein do not necesesprily state or reflect those of the Unitod States Gowernment or any agency thereor. 


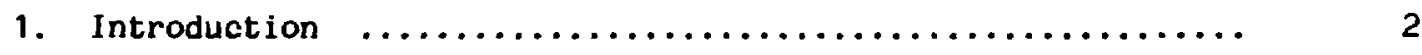

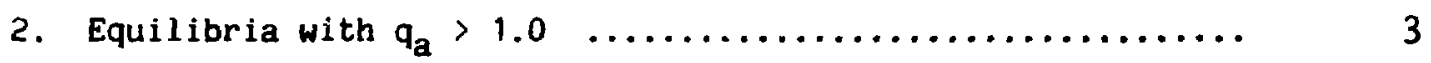

3. Fixed Plasma Parainters for Equilibrium Survey $\ldots \ldots \ldots \ldots \ldots$.

4. Equilibrium Options: Variation with $q_{a} \ldots \ldots \ldots \ldots \ldots \ldots \ldots \ldots$

5. Reference High Field Reactor $\ldots \ldots \ldots \ldots \ldots \ldots \ldots \ldots \ldots \ldots \ldots \ldots .6$

6. Current Drive with High Frequency Fast Waves $\ldots \ldots \ldots \ldots \ldots \ldots . \quad 8$

7. Conclusions $\ldots \ldots \ldots \ldots \ldots \ldots \ldots \ldots \ldots \ldots \ldots \ldots \ldots \ldots \ldots \ldots \ldots$

Acknowledgement $\quad \ldots \ldots \ldots \ldots \ldots \ldots \ldots \ldots \ldots \ldots \ldots \ldots \ldots \ldots \ldots \ldots \ldots \ldots \ldots$.

REFERENCES $\quad \ldots \ldots \ldots \ldots \ldots \ldots \ldots \ldots \ldots \ldots \ldots \ldots \ldots \ldots \ldots \ldots \ldots \ldots \ldots \ldots \ldots . . \ldots \ldots$ 


\section{LIST OF TABLES}

Page

Table 1

Equilibrium Sequence with $q_{a}$ Variation $\ldots \ldots \ldots \ldots$

Table 2

High Field Reactor Reference Parameters

13

\section{LIST OF FIGURES}

Page

Figure 1 Equilibria with $p \sim \tilde{q}^{a}$ and $E$

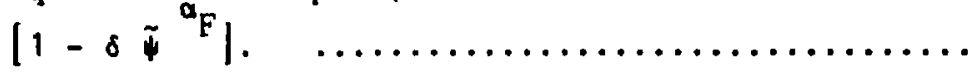

Eigure 2 Equilibrium with $q_{\mathrm{a}}=1.07, \beta_{\mathrm{t}}=0.045$,

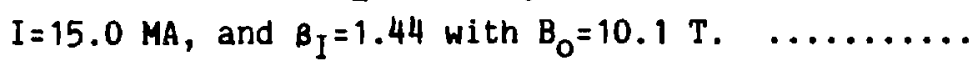

Figure 3 Equilibrium with $q_{a}=1.81, \beta_{t}=0.023$,

$I=10.6 \mathrm{MA}$, and $B_{I}=2.88$ with $B_{0}=14.2 \mathrm{~T}$. . . . . . 18

Figure 4 Same equilibrium as in Figure $3 . \ldots \ldots \ldots \ldots \ldots$

$\begin{array}{lll}\text { Figure } 5 & \text { Poloidal flux contours for reference reactor. .... } 20\end{array}$

Figure 6 Contours of constant toroidal current density

for reference reactor. $\ldots \ldots \ldots \ldots \ldots \ldots \ldots \ldots \ldots . . \ldots 1$

Figure 7 Normalized density for reference reactor:

$n_{e} / n_{e o}=\tilde{\psi}^{0.3}$.

Figure 8 Normalized temperature for reference reactor:

$\mathrm{T}_{\mathrm{e}} / \mathrm{T}_{\mathrm{eo}}=\tilde{\psi}^{0.9}$.

Figure 9 Equilibrium with fast-wave seed current and bootstrap contribution: a) chain dashed curve is $\mathrm{H}$, dashed is wave-driven $\mathrm{G}$ ( 3 rays), dotted is $\mathrm{G}+\mathrm{H}$, andsolid is target $\left\langle\mathrm{J}_{\|} \mathrm{B}\right\rangle$ ico be reproduced; b) $J_{t}(R, 0) j$, c) ray trajectories;

d) $q(R, 0)$. 
MAXIMAL BOOTSTRAP CURRENT TOKAMAK EQUILIBRIA IN THE FIRST STABILITY REGIME

by

David A. Ehst

Kenneth Evans, Jr.

\begin{abstract}
A series of tokamak equilibria are studied in order to identify characteristics which may maximize the proportion of toroidal current naturally provided by the bootstrap effect. These plasmas are typical of high field reactors considered by the ARIES [Advanced Reactor Innovation and Evaluation Study ] collaboration and are assumed to have rather flat density profiles and broad pressure profiles. With the use of noninductive current drive to provide the seed current it is possible to operate with $q_{a x i s}=2.0$; this results in a (bootstrap-assisted) current drive power of $\mathrm{P}_{C D}^{\mathrm{B}}=117 \mathrm{MW}$ and a figure of merit $\gamma^{B}=1.12$ for a reference reactor with $T_{e} \approx 21 \mathrm{keV}$. For the reference reactor $P_{f}=2880 \mathrm{MW}$ so $Q=24$. Without the bootstrap effect the absorbed current drive power would be $P_{C D}=285 \mathrm{MW}$, so $r \equiv 1-\left(\gamma / \gamma^{B}\right)=0.59$.
\end{abstract}




\section{Introduction}

Detailed comparisons of steady-state and pulsed, onmic burn cycles for tokamak reactors have shown there is a minimum current drive efficiency needed to permit economical operation in the steady state. In terms of the normalized efficiency, $\gamma \equiv \bar{n}_{e} I_{0} R_{0} / P_{C D}$, where $P_{C D}$ is the auxiliary power absorbed in the plasma, it was found [1] that $r \geqslant 0.4\left(10^{20} \mathrm{~A}-\mathrm{m}^{-2}-\mathrm{W}^{-1}\right)$ is needed to make steady state more attractive than pulsed operation. Unfortunately, calculations of MHD equilibria in the first stability regime, generated by $r f$ current drive alone [2], have yielded somewhat disappointing results: although $\gamma \approx 0.4$ looks possible, it may be difficult to increase the value much more.

Recently, however, there has been experimental evidence that the neoclassical bootstrap current spontaneously arises in tokamak experiments. This is most encouraging because it reduces the amount of auxiliary power. needed to maintain a reactor. plasma in equilibrium. With the bootstrap effect, the absorbed power, $\mathrm{P}^{\mathrm{B}} \mathrm{CD}$, is smaller, and the effective figure of merit, $\gamma^{B} \equiv \bar{n}_{e} R_{0} I_{o} / P_{C D}^{B}$, is larger than without the bootstrap effect. A survey of reactor ejuilibria [3] recently revealed that $\gamma^{B}>1.0$ is possible under certain conditions, especially when peaked density profiles occur in the plasma. Correspondingly, the fraction of the current provided by the bootstrap effect, approximately $\Gamma \equiv 1-\left(\gamma / \gamma^{B}\right)$, can exceed $50 \%$ and be as largo as $90 \%$.

The ARIES effort to design a high-field, first-regime (low beta) reactor highlighted the concern that reactor-sized plasmas will be difficult to fuel near the magnetic axis, and this will lead to quite flat density profiles. Based on previous work [3] we would expect the bootstrap effect to contribute only a small fraction $(\Gamma \leq 0.3)$ of the equilibrium current for low poloidal beta plasmas under these conditions. The purpose of the present communication is to demonstrate that even with flat densities it is possible to have $\Gamma \geq 0.5$ in a high field reactor. The guiding principle in our study is that raising the axis safety factor, $q_{a}$, should reduce the toroidal current density, $j_{t}$, at the magnetic axis. Since most of the noninductive current drive power is absorbed near the axis to provide the seed current, the greatest savings in auxiliary power should be achieved by operating at large values of $q_{a}$. 


\section{Equilibria with $q_{a}>1.0$}

There is increasing evidence that long pulse tokamak operation at $q_{a}$, 1.0 is possible witit noninductive current drive. ASDEX experiments [4] with lower hybrid current drive (LHCD) provided a clear demonstration of stable operation with $q_{a}=1.3$. Similarly, on Versator II LHCD provided $q_{a} \simeq 4.4$ [5], and these discharges proved to be very quiescent even though the poloidal beta was very large - $B_{I} / A \cong 1.2$, where $A$ denotes the aspect ratio. Low current operation of DIIID has been maintained by neutral beam current drive $(N B C D)$, and these experiments [6] also resulted in high poloidal beta operation, ${ }_{B_{I}} / A=1.4$; magnetic diagnostics suggest $q_{a}>1.0$ for these discharges [7]. On typical DIIID shots the bootstrap effect is found to supply $\sim 5-7 \%$ of the total equilibrium current.

Theoretical studies further increase our confidence that equilibria with large $q_{a}$ can be stable at the modest beta values of the first stability regime. A particular example was studied which is similar to the bootstrap equilibria discussed in the following sections. This test case has $A=6.0, a$ mild elongation, $k=1.3$, and a small triangularity, $d=0.25$. The pressure profile has the functional form considered below, $p(\psi)=p_{0} \tilde{\psi} \boldsymbol{\alpha}$, where $\alpha=1.4$ and $\tilde{\psi}$ is the normalized poloidal flux function which is one at the axis and zero at the edge. When $\mathrm{q}_{a}=1.25$, and for a boundary safety factor $\mathrm{q}_{\mathrm{b}}=2.15$, this equilibrium was stable to all ballooning modes ( $N_{\text {crit }}+\infty$ ) and to $n=1$ kinks with a conducting wall at 0.3-0.4 times the minor radius, with $B_{t}=0.05$ and $B_{I} / A=0.63$. The normalized ratio of beta to toroidal current is given by $\mathrm{g} \equiv \mathrm{B}_{\mathrm{t}} \mathrm{a} \mathrm{B}_{\mathrm{o}} \mathrm{I}_{\mathrm{O}}=0.0744$, which is roughly twice the conventional Troyon value, $\mathbf{g}_{\mathrm{T}} \simeq 0.03$. Presumably, operation at lower beta, e.g., $\boldsymbol{B}_{\mathbf{t}}=0.02$ and $\mathbf{g}=0.03$, would provide even better stability.

\section{Fixed Plasma Parameters for Equilibrium Survey}

For this study we set $A=6.0, k=2.25$, and $d=0.5$. This geometry was selected after preliminary considerations of a high-field reactor by the ARIES group. The large $k$ simplifies the design of a double-null poloidal divertor, although feedback stabilization of the axisymetric mode is problematic. While the optimum geometry for this reactor is not presently settled, we expect that the choice among these parameters is not crucial to the current drive/bootstrap results. 
The equilibrium pressure profile in a reactor is difficult to predict. Early numerical studies [8] of kink and ballooning modes clearly demonstrateu enhanced stability for $p(\psi) \sim \tilde{\psi}^{\alpha}$ as $a$ is reduced from 2.0 to 1.4 to 1.2 . Broad pressure $(\alpha=1.2)$ is thus desirable to achieve maximum MHD stability (largest value of $\mathrm{g}$ ). Initial transport calculations for ARIES [9] indicated, however, that the pressure could be quite peaked due to the central alphit heating. Nevertheless, it is plausible that such peaked profiles will nor. appear, as temperature gradient (kinetic) instabilities will tend to flatten the temperature profile.

The profile argument is as follows. Central fueling is believed to be extremely difficult at reactor temperatures with line average densities 2 . $10^{20} \mathrm{~m}^{-2}$. Conventional fueling techniques such as pellet injection will not penetrate far, even with pellet velocities? $10 \mathrm{~km} / \mathrm{s}$. If we follow the ARIES high-field reactor philosophy of using relatively proven plasma physics ("ITER physics"), we conclude that the electron density profile, $\mathrm{n}_{\mathrm{e}}(\psi)=$ $n_{80} \tilde{\psi}^{n}$, is fairly flat. Simulations for ARIES [9] suggest $a_{n} \leq 0.1$, and ITER guidelines are presently $a_{n} \approx 0.5$. For the present study we select

$$
a_{n}=0.3
$$

The temperature profile is assumed to be $T(\psi) \sim \tilde{\psi}^{{ }^{a}} T$, and the logarithmic ratio of temperature and density gradients is then $n=d(\ell n T) /(d$ ln $n)=$ $a_{\mathrm{T}} / a_{n}$. A large body of theory suggests that drift waves can be driven unstable when $\eta \geq 2$ for either electrons or ions in the confined plasma. The resulting turbulence will enhance thermal transport, and presumably the instabilities will saturate at some value of $n$ greater than two. We select

$$
a_{T}=0.9
$$

for our present study. This results in $\eta=3.0$ and has $a_{n}+a_{T}=\alpha=1.2$. [More elaborate profiles could be investigated in the future; for example, flatter pressure profiles can be represented by $p(\psi) \sim p_{0}\left[1-(1-\tilde{\psi})^{a_{1}}\right]^{2}$. We may wish to defer such studies until more reilable transport code predictions are provided, however.] 
We have computed a variety of equilibria (with different safety factors), for the specified geometry and pressure profiles. The remaining qu itity which we have fixed in these calculations is the normalized ratio of Liva to current. We have selectd $g=0.030$. This is a conservative beta limit; ITER guidelines specify $\mathrm{g}=0.030-0.033$ for steady state operation.

\section{Equilibrium Options: Variation with $q_{a}$}

Noninductive current drive may truly provide an opportunity to control the current profile and safety factor. Unlike with ohmic cur:ent drive, there is no apparent constraint forcing $q_{a}$ to the vicinity of unity. Since stability does not appear to deteriorate with moderate increases of $q_{a}$, we can investigate the benefit of large $q_{a}$ equilibria to the problem of noninductive current drive. We do constrain $q(\psi)$ to monotonic, however, to avoid double tearing mode instabilities.

The MHD equilibrium candidates are modelled with a diamagnetism function $F(\psi) \equiv R \quad B_{t}$ with $F(\psi)=F_{b}\left(1-\delta \tilde{\psi}^{\alpha}\right)^{1 / 2}$. For a fixed geometry ( $A=6$, $\kappa=2.25, d=0.5)$, pressure profile $(\alpha=1.2)$, and $q_{a}(=1.0)$ a matrix of equilibria at different $\beta_{t}$ and $q_{b}$ values is created by varying the diamagnetism variables $\delta$ and $\alpha_{F}$. Figure 1 plots the locus of numerous equilibria which were found. The total toroidal current for a 2-D MHD equilibrium is not a simple function of $q_{b}$, since the toroidal current density profile $J_{t}(R, Z)$ varies with $\beta_{t}$. In the figure we point out that equilibria with $B_{t} \leq 0.041$ are all paramagnetic and have $B=B_{t} a B_{o} / I_{o}<0.030$. The circles at $B_{t} \geqslant 0.058$ denote equilibria with $g>0.030$. The triangles (and, in general, the "forbidden" region around $B_{t} \approx 0.04$ with $a_{b} \geq 3$ ) are beyond the convergence limit of the code; these limiting equilibria feature surface current density gradients which are very large.

For our purposes we concentrate on the sequence in Figure 1 labelled by $a_{F}=1.2$. Each point in the sequence is scaled to a new equilibrium with $\mathbf{B} \equiv 0.030$ by an appropriate increase of $q_{a}[10]$. The resulting set of equilibria, all with $g=0.030$ but different $q_{a}$ values, is given in Table $I$.

Table I quantifies the benefits of raising $q_{a}$. Referring to the table, we note as $q_{a}$ increases and $\beta_{t}$ decreases that the equilibrium current decreases significantly. If the very large toroidal field $\left(B_{0} \geq 15 T\right.$ ) can be 
provided, then the lowest $\beta_{t}$ equilibria in the sequence are most attractive from the point of view of steady-state current drive. Also evident is a reduction in the toroidal current density at the magnetic axis, $j_{t a} \equiv j_{t}\left(R_{\text {mag }}, 0\right)$, as $q_{a}$ increases. Figures 2 and 3 show that this reduction in $j_{\text {ta }}$ is associated with a change in the current density profile; at the largest $q_{a}$ (highest poloidal beta) the curcent density maximizes further away from the magnetic axis (where the pressure profile peaks). Additional advantages of large $q_{a}$ equilibria are the increase of Shafrano's poloidal beta, $B_{I}$, and the slight increase in the pressure peaking in configuration space, given by the ratio of peak to average pressure, $\mathrm{p}_{0} / \overline{\mathrm{p}}$. In Ref. 3 it was shown that the bootstrap fraction $(\Omega \Gamma)$ is proportional to the factor $\left(p_{0} / \bar{p}\right) B_{I}$.

\section{Reference High Field Reactor}

We will proceed to the current drive calculation by concentrating on a single equilibrium. We select the case with $q_{a}=1.808, q_{b}=4.88$, and $\beta_{t}=0.0225$. This has the profiles given in Fig. 3 and Fig. 4. Poloidal flux and constant toroidal current density contours are shown in Figs. 5 and 6 . The corresponding density and temperature profiles in the midplane are shown in Figs. 7 and 8 . The intermediate step facing us, now that the equilibrium has been chosen, is to select the proper average density, temperatures, major radius, and magnetic field to enhance the steady state reactor performance. These variables and the current drive calculation must be consistent with confinement and the plasma power balance. We accomplish the power balance calculation by using the 2-D flux surface distribution (Fig. 5) in the TRAC II code, which averages the power balance over ten flux surfaces.

Several constraints occur for the power balance:

$$
\begin{aligned}
& \text { a. neutron wall load (average) } \equiv W_{n} \simeq 5.0 \mathrm{MW} \cdot \mathrm{m}^{-2} \\
& \text { b. fusion power } P_{\mathrm{f}} \simeq 2700 \mathrm{MW}
\end{aligned}
$$

These two constraints, which stem from economic considerations, lead us to select a major radius $R_{0}=6.0 \mathrm{~m}$ for our tokamak geometry. 
c. maximum field at $\mathrm{TF}$ coil $\mathrm{B}_{\mathrm{M}} \leq 24 \mathrm{~T}$

Invariably current drive power, $\mathrm{P}_{C D}$, is reduced by operating at the highest $T_{e}$, which ultimately forces us to design for the highest toroidal field which can be created.

d. $\bar{n}_{\mathrm{e}}=2 \times 10^{20} \mathrm{in}^{-3}$

The divertor, used for impurity control, requires $n_{e} \geq 1.5 \times 10^{20} \mathrm{~m}^{-3}$ at the midplane of the divertor flux surface. This forces the average density to be somewhat larger. However, operational experience with tokamaks indicates there is an upper linit to $\bar{n}_{e}$ which must be imposed in order to avoid disruptions. In the absence of auxiliary heating, the Murakani and Greenwald density limits are both below $2 \times 10^{20} \mathrm{~m}^{-3}$. However, auxiliary heating increases the $\bar{n}_{e}$ limit, and we presently assume $-2 \times 10^{20} \mathrm{~m}^{-3}$ is achievable.
e. $z_{\text {eff }}=1.5$
f. confinement

The power balance includes additional heat input $\left(\mathrm{P}_{\text {aux }}\right.$ ) due to the absorbed current drive power, so the plasma is always subignited. This permits smaller. electron energy confinement time, ' $e$, than is needed for pure ignitior. However, $\tau_{e}$ should be afproximately consistent with the predictions of various scaling laws.

A reference reactor which meets our requirements is presented in Table II. The auxiliary heating, Paux, which is specified as an input to the calculation, anticipates the results of the current drive calculation. The results are relatively insensitive to the actual value of $P_{\text {aux }}$ chosen -- $\bar{n}_{e}$ and temperatures are roughily constant for $100 \mathrm{MN} \leq \mathrm{P}_{\text {aux }} \leq 200 \mathrm{MN}$. $P_{\text {aux }} \operatorname{most} I \mathrm{y}$ affects the required electron energy confinement time. For the reference design the neoclassical ion energy confinement time is ${ }^{\top} N C=75 \mathrm{~s}$. The neoAlcator confinement time is $\tau_{\text {NA }}=23 \mathrm{~s}$; the Odajima-Shimomura offset - linear scaling predicts $L$ mode global confinewent to be $\tau_{O S}=0.42 \mathrm{~s}$, while Kaye-Big scaling predicts ${ }^{T_{K B}}=0.35 \mathrm{~s}$. Thus, divertor operation with $\mathrm{H}$ mode factors of - 2-3 may be needed to achieve this particular power balance. 
The parameters most relevant to current drive calculations are the temperatures, electron density, and total current. The field strength $B_{0}$ will have an influence on the wave frequencies chosen for current drive. These values, from Table II, are used in the next section.

\section{Current Drive with High Frequency Fast Waves}

The central current density required for our equilibrium is provided by fast waves at frequencies well above the fundanental cyclotron frequencies ( $100 \mathrm{MHz}$ for deuterium), and ion power absorption will be found to be negligible. Near the surface a small anount of lower hybrid wave power is provided at a frequency $f=8 \mathrm{GHz}$, which is adequately high to avoid damping on nonthermal alphas.

First the current drive problem is solved in the absence of any bootstrap contribution. The calculation is standard [2] and can be accomplished by the following idealized power spectrum:

$$
\begin{aligned}
& P=13.9 \mathrm{MW} \mathrm{e} \mathrm{n}_{1}=3.2 \\
& f=8.0 \mathrm{GHz}(\mathrm{LH}) \quad P=16.9 \mathrm{MH} \text { e } n_{1}=2.2 \\
& P=14.3 \mathrm{~m} \mathrm{e} n_{1}=1.8 \\
& f=2.45 \mathrm{GHz}(\mathrm{FW}) \quad P=145 \mathrm{MW} \quad \mathrm{n}_{\mathbf{l}}=2.0 \\
& f=0.80 \mathrm{GHz}(\mathrm{FW}) \quad P=94.9 \mathrm{MW} \text { e } n_{1}=2.5
\end{aligned}
$$

The total power is $P_{C D}=285 \mathrm{MW}$, which results in $Y=0.46$ for $\bar{n}_{e}=2.1 \times$ $10^{20} \mathrm{~m}^{-3}, I_{0}=10.6 \mathrm{MA}$, and $R_{0}=6.0 \mathrm{~m}$ at $T_{e}=22 \mathrm{keV}$ and $Z_{\text {eff }}=1.5$. [By comparison the formula in Ref. 2 would predict $Y=0.42$, although the formula was derived for equilibria with $q_{a}=1.0, a=1.4$, and $a_{n}=1.1$ (peaked density profiles).]

The current drive calculation is next performed including the bootstrap terms [3]. Figure 9a displays the important functions in this problem. The solid curve is $\langle J, B\rangle /\left\langle B^{2}\right\rangle$ required for our equilibrium, where \langle\rangle denotes the 
flux surface average and $j_{\|}$is the component of current flowing along the field line. Note that $\left\langle j_{\|} B\right\rangle$ peaks at the magnetic axis $(\tilde{\psi}=1)$ even though $j_{t}$ peaks off axis (Fig. 3 ). The bootstrap contribution to $\left\langle j_{y} B\right\rangle$ is the chain-dashed curve, $H(\psi)=\left\langle j_{\|}^{B} B\right\rangle /\left\langle B^{2}\right\rangle . \quad H$ is substantial and provides nearly all the required $\left\langle j_{\|} B\right\rangle$ near the plasma surface $(\tilde{\psi}=0)$. Near the axis the plasma is in the plateau regime and $H$ is very small, so the remaining porticn of $\left\langle j_{\|} B\right\rangle$ must be provided by the wave-driven currents. This complemeritary function, $G(\psi)=\left\langle j_{\|}^{R F} B\right\rangle /\left\langle B^{2}\right\rangle$, can be produced by three waves (dashed curves in Fig. 9a):

$$
\begin{array}{ll}
f=8.0 \mathrm{GHz}(\mathrm{LH}) & P=11.4 \mathrm{MW} e \mathrm{n}_{\|}=3.2 \\
f=2.45 \mathrm{GHz}(\mathrm{FW}) & P=33.0 \mathrm{MW} e \mathrm{n}_{\|}=2.0 \\
f=0.80 \mathrm{GHz}(\mathrm{FW}) & P=72.4 \mathrm{MW} e \mathrm{n}_{\|}=2.5
\end{array}
$$

The ray-tracing, current drive and equilibrium calculations are iterated, and the stated solution is found to be numerically stable with $j_{t}(R, 0)$ and $q(R, 0)$ as given in Fig. 9. The slight nonmonotonic behavior of $q(\psi)$ is believed to be only a cosmetic blemish; better $q(\psi)$ tailoring is numerically possible by using many more rays in the power spectrum in order to more smoothly illuminate the plasma near the magnetic axis.

Compared to the former current drive calculation, much less external power is needed to create this equilibrium with its large bootstrap current -$\mathrm{P}_{\mathrm{CD}}^{\mathrm{B}}=117 \mathrm{MW}--$ and the bootstrap-aided figure of merit is larger, $\gamma^{\mathrm{B}}=1.12$.

Thus, for the equilibrium considered we find there is a large bootstrap fraction, $\Gamma=1-\left(\mathrm{Y} / \mathrm{Y}^{\mathrm{B}}\right)=0.59$. This value of $r$, incidentally, is not much different from the value predicted by the formula in Ref. 3, although the calculations in the reference were for equilibria with $q_{a}=1.1$. We would also expect approximately the same $r$ if neutral beam current drive were used. 


\section{Conclusions}

Thanks to "free" current generation provided by the bootstrap effect we find $\Gamma \geqslant 0.5$ is possible even in a reactor with rather flat density profiles. This is possible if the noninductive seed current is used to generate a high poloidal beta equilibrium with $q_{a}=2.0$. The resulting high-field reactor has $Q=24$.

Future studies should evaluate variations of $\Gamma$ with $a_{n}$, especialiy consiưering $a_{n} \leq 0.2$. A systematic evaluation of $r$ vs. $q_{a}$ (e.g., for Table $I$ ) would be desirable; and flatter pressure functions could be explored with the possibility of increasing $q_{a}$ and $r$ still further. Finally, the MHD stability of large $q_{a}$ equilibria needs to be quantified.

\section{Acknowledgement}

This work was stimulated by discussions with D. Steiner. 


\section{REFERENCES}

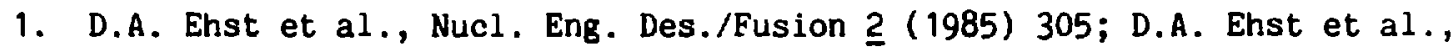
Nucl Eng. Des./Fusion $\underline{2}$ (1985) 319; D.A. Ehst et al., Nucl. Eng. Des./Fusion 3 (1985) 113.

2. D.A. Ehst, K. Evans, Jr., Nucl. Fusion $\underline{27}$ (1987) 1267.

3. M-Y. Hsiao, D.A. Enst, K. Evans, Jr., Nucl. Fusion to be published.

4. K. McCormick et al., Phys. Rev. Lett. $\underline{58}$ (1987) 491.

5. S.C. Luckhardt et al., MIT Plasma Fusion Center report PFC/JA-88-24 (1988).

6. J. Kim et al., "Neutral Beam Current Drive Experiments of DIID," Lawrence Livermore National Laboratory report UCRL-99937 Preprint; presented at 13th Ann. Mtg APS/DPP (1988).

7. T. Simonen, presented at U.S.-Japan Workshop on Advanced Current Drive Options, Livermore, CA (1988).

8. A.M.M. Todd et al., Nucl Fusion 19 (1979) 743.

9. C. Singer, private comunication.

10. D.A. Ehst et al., J. Fusion Energy 2 (1982) 83, Appendix A. 


\section{Table I}

Equilibrium Sequence with $q_{a}$ Variation

$$
A=6.0, k=2.25, d=0.25, a=1.2, R_{0}=6.0 \mathrm{~m}, \alpha_{F}=1.2
$$

Toroidal current and $B_{0}$ are adjusted so $B_{t}^{2} B_{0}^{4}=$ constant;

$$
\mathrm{g}=\mathrm{B}_{\mathrm{t}} \mathrm{aB}_{\mathrm{o}} / \mathrm{I}_{\mathrm{o}}=0.030\left(\mathrm{~m}-\mathrm{T}-\mathrm{MA}^{-1}\right)
$$

\begin{tabular}{|c|c|c|c|c|c|c|c|c|}
\hline Well Depth & $q_{a}$ & $q_{b}$ & $\begin{array}{c}B_{t} \\
q^{\prime}\end{array}$ & $\begin{array}{l}\mathrm{B}_{0} \\
(\mathrm{~T})\end{array}$ & $\begin{array}{c}I_{0} \\
(M A)\end{array}$ & $\begin{array}{c}J_{t a} \\
\left(M A-m^{-2}\right)\end{array}$ & ${ }^{B} I$ & $p_{o} / \bar{p}$ \\
\hline .0324 & 1.073 & 2.21 & 4.48 & 10.1 & 15.0 & 2.85 & 1.44 & 2.41 \\
\hline .0364 & 1.242 & 2.67 & 3.75 & 11.0 & 13.8 & 2.72 & 1.71 & 2.44 \\
\hline .0381 & 1.438 & 3.34 & 3.11 & 12.1 & 12.4 & 2.52 & 2.10 & 2.45 \\
\hline .0366 & 1. 616 & 4.00 & 2.63 & 13.1 & 11.6 & 2.40 & 2.43 & 2.47 \\
\hline .0350 & 1.808 & 4.88 & 2.25 & 14.2 & 10.6 & 2.34 & 2.88 & 2.52 \\
\hline .0317 & 2.070 & 6.35 & 1.82 & 15.8 & 9.6 & 2.22 & 3.52 & 2.56 \\
\hline
\end{tabular}


Table II

High Field Reactor Reference Parameters

$\begin{array}{lll}\text { Parameter Uniable Units Value } & \text { Variable }\end{array}$

\begin{tabular}{|c|c|c|c|}
\hline aspect ratio & A & & 6.0 \\
\hline elongation & k & & 2.25 \\
\hline triangularity & d & & 0.5 \\
\hline pressure profile exponent & $\mathbf{a}$ & & 1.2 \\
\hline diamagnetism exponent & $a_{F}$ & & 1.2 \\
\hline well depth & 6 & & 0.0350 \\
\hline axis safety factor & $q_{a}$ & & 1.808 \\
\hline boundary safety factor (limiter) & $q_{b}$ & & 4.88 \\
\hline cylindrical safety factor & $\mathbf{q}_{*}$ & & 4.37 \\
\hline volume average toroidal beta & $B_{t}$ & & 0.0225 \\
\hline r.m.s. beta & B* & & 0.0280 \\
\hline Shafranov poloidal beta & $B_{I}$ & & 2.87 \\
\hline peak to average pressure ratio & $p_{0} / \bar{p}$ & & 2.52 \\
\hline magnetic axis fractional shift & $\left(R_{\operatorname{mag}}-R_{0}\right) / a$ & & 0.157 \\
\hline "Troyon" ratio & $\mathbf{g}$ & & 0.030 \\
\hline major radius & $R_{0}$ & $\mathbf{m}$ & 6.0 \\
\hline minor radius & $\mathbf{a}$ & $\mathbf{m}$ & 1.0 \\
\hline inboard scrapeoff & $\Delta \underline{i}$ & m & 0.10 \\
\hline inboard blanket plus shield & $\Delta_{B / S}^{i}$ & $\mathbf{m}$ & 1.25 \\
\hline plasma volume & $v_{p}$ & $\mathrm{~m}^{3}$ & 253.0 \\
\hline first wall area & $A_{w}$ & $\mathbf{m}^{2}$ & -430.0 \\
\hline blanket energy multiplication & $M_{\mathrm{B}}$ & & 1.25 \\
\hline thermal power conversion efficiency & $n_{\text {th }}$ & & 0.40 \\
\hline current driver efficiency & $n_{F W}$ & & 0.65 \\
\hline
\end{tabular}


Table II

High Field Reactor Reference Parameters

(continued)

\begin{tabular}{|c|c|c|c|}
\hline Parameter & Vaitiable & Units & Value \\
\hline density profile exponent & $a_{n}$ & & 0.3 \\
\hline temperature profile exponent & $a_{T}$ & & 0.9 \\
\hline$d \ln \mathrm{T}_{e} / d \ln \mathrm{n}_{e}$ & $n_{e}$ & & 3.0 \\
\hline minimum electron collisionality & $v_{* e}$ & & 0.026 \\
\hline minimum ion collisionality & $v * \mathbf{i}$ & & 0.011 \\
\hline fusion power & $P_{f}$ & $\mathbf{M H}$ & 2880 \\
\hline alpha power & $\mathrm{P}_{\mathrm{a}}$ & MH & 576. \\
\hline neutron power & $P_{n}$ & MW & 2304 \\
\hline auxiliary heating (electrons) & $P_{\text {aux }}$ & MW & -120 \\
\hline neutron average wall load & $w_{n}$ & $M W-m^{-2}$ & 5.36 \\
\hline plasma power density & $\mathrm{p}_{\mathrm{f}}$ & $M N-m^{-3}$ & 11.4 \\
\hline volume average electron temperature & $\mathrm{T}_{\mathrm{e}}$ & $\mathrm{keV}$ & 22.0 \\
\hline peak electron temperature & $\mathrm{T}_{\text {eo }}$ & keV & 44.6 \\
\hline average ion temperature & $T_{i}$ & $10^{20} \mathrm{~m}^{-3}$ & 20.2 \\
\hline average electron density & $\bar{n}_{e}$ & $10^{20} \mathrm{~m}^{-3}$ & 2.09 \\
\hline peak electron density & $n_{e o}$ & $10^{20} \mathrm{~m}^{-3}$ & 2.80 \\
\hline effective ion charge (light impurities) & $Z_{\text {eff }}$ & & 1.5 \\
\hline fuel density (50\$ DT) average & $\bar{n}_{\mathrm{DT}}$ & $10^{20} \mathrm{~m}^{-3}$ & 1.70 \\
\hline required electron energy confinement & $\tau_{e}$ & $\mathbf{s}$ & 1.12 \\
\hline required ion energy confinement & $\boldsymbol{\tau}_{\mathbf{i}}$ & $\mathbf{s}$ & 0.71 \\
\hline peak pressure & $\mathrm{p}_{0}$ & $\mathrm{MPa}$ & 4.53 \\
\hline vacuum toroidal field on axis & $\mathrm{B}_{\mathrm{O}}$ & $\mathrm{T}$ & 14.2 \\
\hline maximum field, at TFC & $\mathrm{B}_{\mathbf{M}}$ & $\mathbf{T}$ & 23.2 \\
\hline plasma toroidal current & $I_{0}$ & MA & 10.6 \\
\hline $\begin{array}{l}\text { toroidal current density } \\
\text { at magnetic axis }\end{array}$ & $j_{\text {ta }}$ & $M A-m^{-2}$ & 2.34 \\
\hline
\end{tabular}


Table II

High Field Reactor Reference Parameters

(continued)

$\begin{array}{lll}\text { Parameter Variable Units Value } & \text { Va }\end{array}$

thermal power $\left(P_{\alpha}+P_{\text {aux }}+M_{B} \cdot P_{n}\right)$

gross electric $\left(n_{t h} \cdot P_{t h}\right)$

current drive, electric power

$$
\left(P_{\text {aux }} \cdot n_{F W}^{-1}\right. \text { ) }
$$

net electric $\left(\mathrm{P}_{\mathrm{g}}-0.06 \cdot \mathrm{P}_{\mathbf{g}}-\mathrm{P}_{\mathrm{CD}}^{\mathrm{e}}\right)$

plasma power multiplication $\left(\mathrm{P}_{f} / \mathrm{P}_{\text {aux }}\right)$

net thermal efficiency

$\begin{array}{llr}\mathbf{P}_{\text {th }} & \text { MW } & 3576 . \\ \mathbf{P}_{\mathbf{B}} & \text { MW } & 1430 . \\ \mathbf{P}_{\text {CD }}^{e^{2}} & \text { MW } & 185 .\end{array}$

$P_{\text {net }}$

MH 1160.

$\mathbf{Q}$

24.

$P_{\text {net }} / P_{\text {th }}$

0.32 


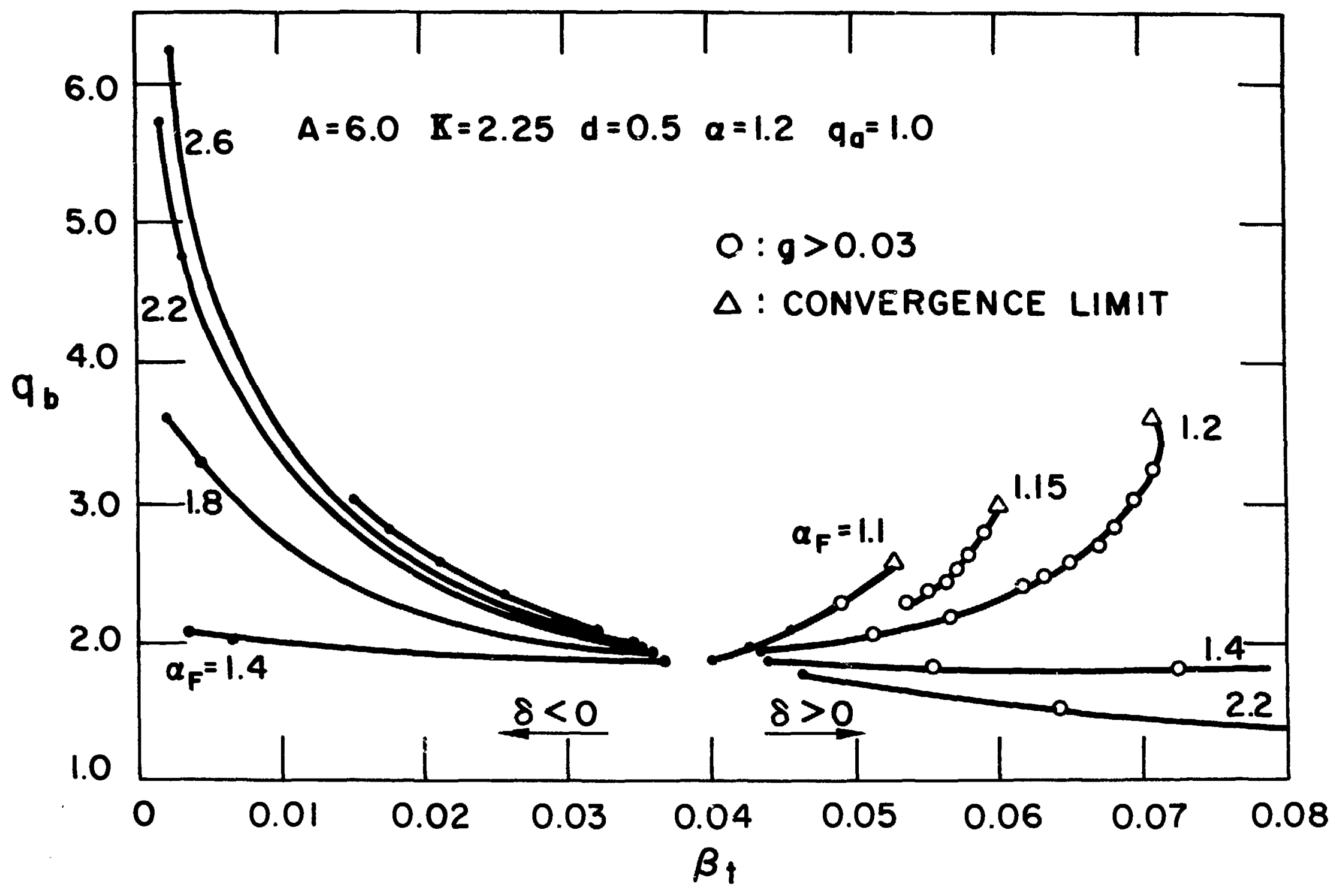

Figure 1. Equilibria with $p \sim \tilde{\psi}^{\alpha}$ and $F \sim\left[1-\delta \tilde{\psi}^{\alpha} F\right]$. 
Psi

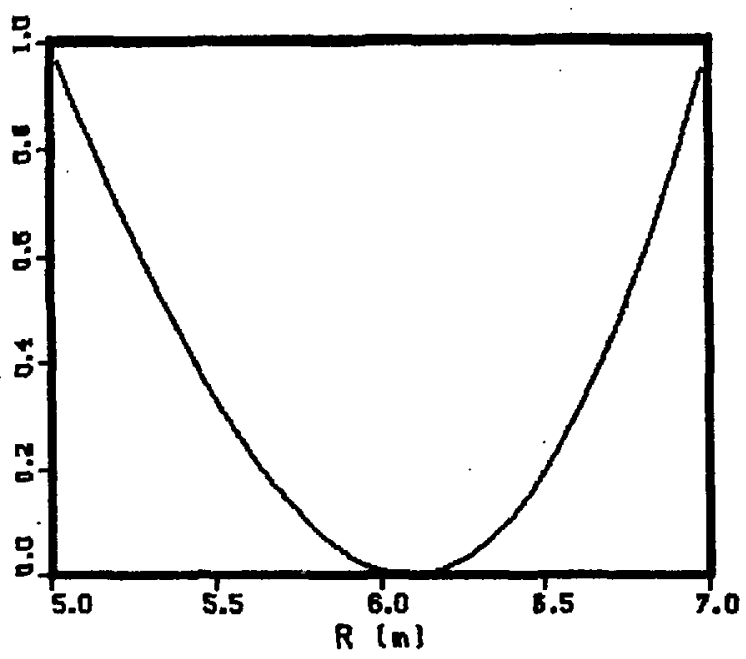

$\stackrel{1}{2}$

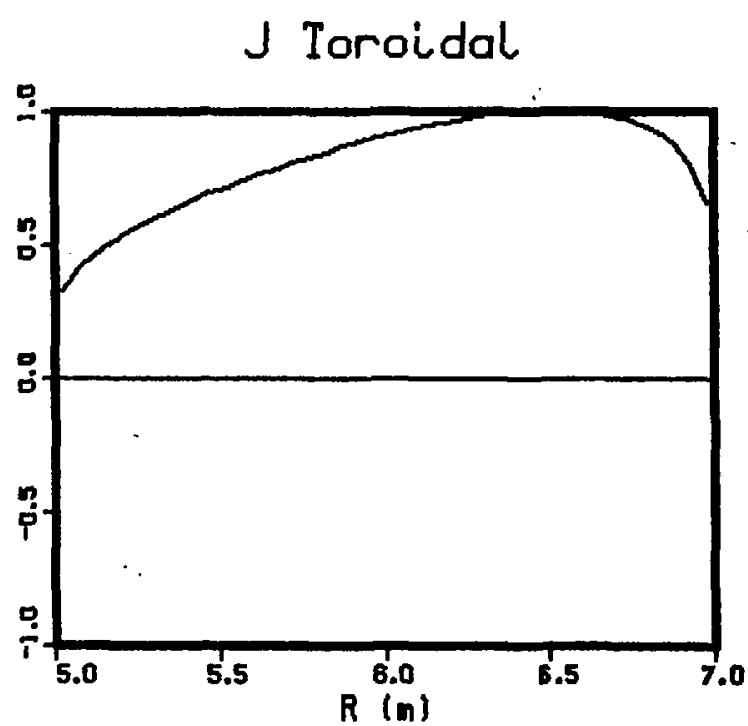

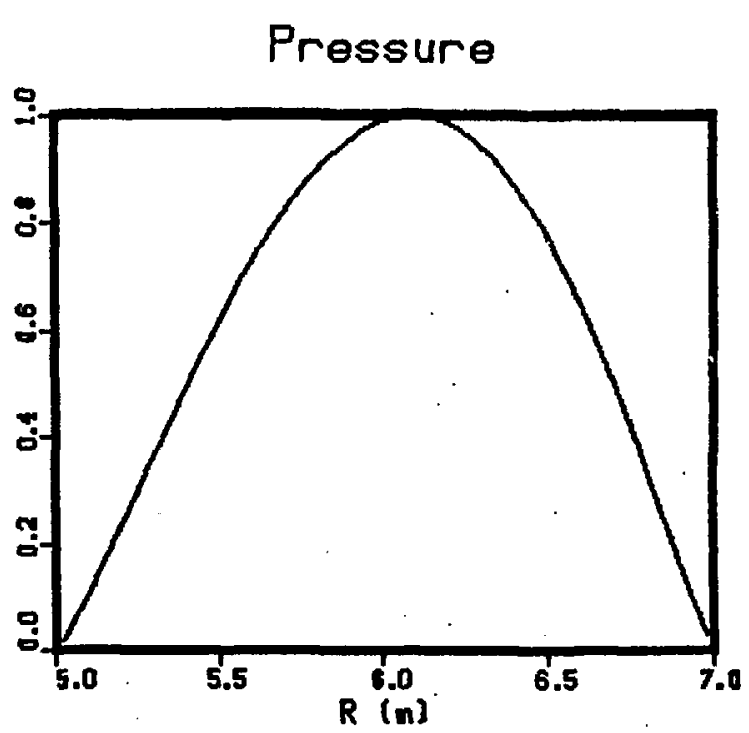

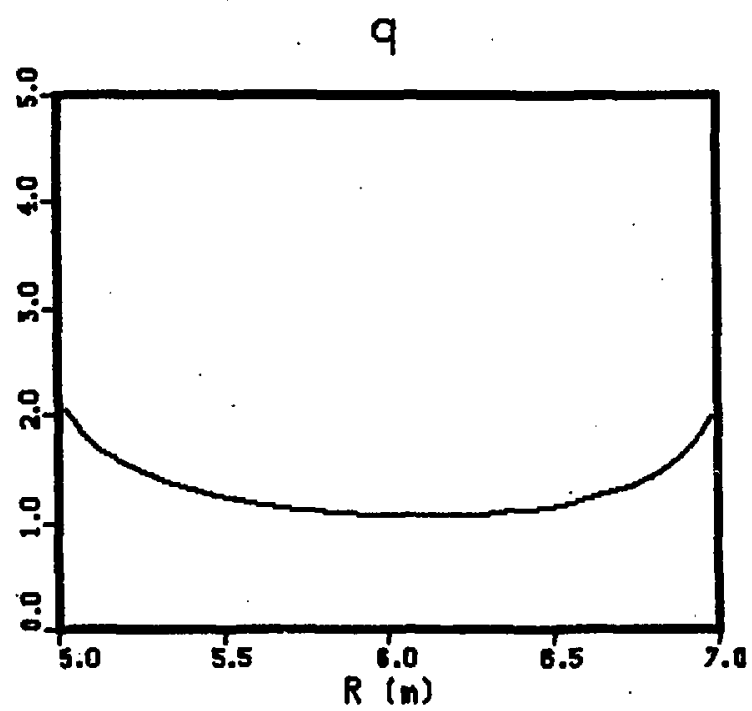

Figure 2. Equilibrium with $q_{a}=1.07, B_{t}=0.045, I=15.0 \mathrm{MA}$, and $B_{I}=1.44$ with $B_{0}=10.1 \mathrm{~T}$. 

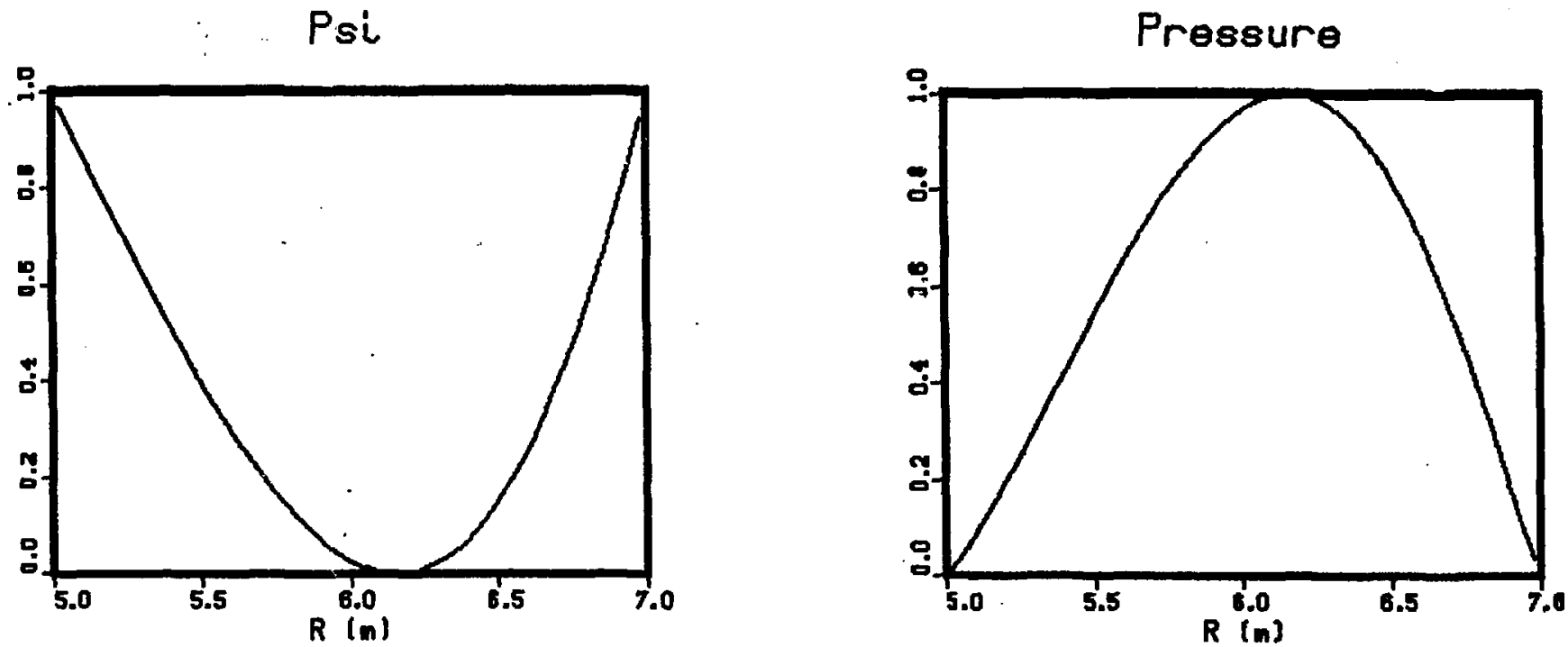

$\stackrel{1}{\infty}$
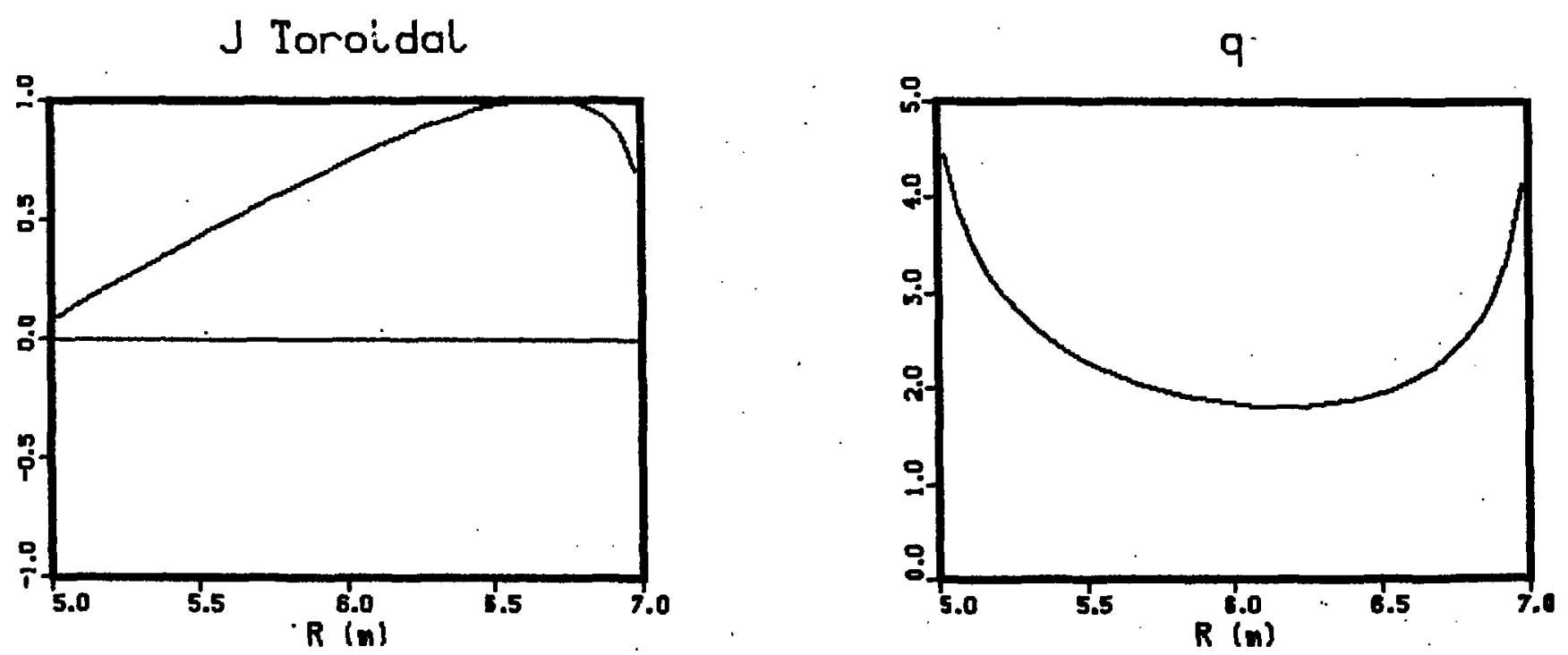

Figure 3. Equilibrium with $q_{a}=1.81, B_{t}=0.023, I=10.6 \mathrm{MA}$, and $B_{I}=2.88$ with $B_{0}=14.2 \mathrm{~T}$. 

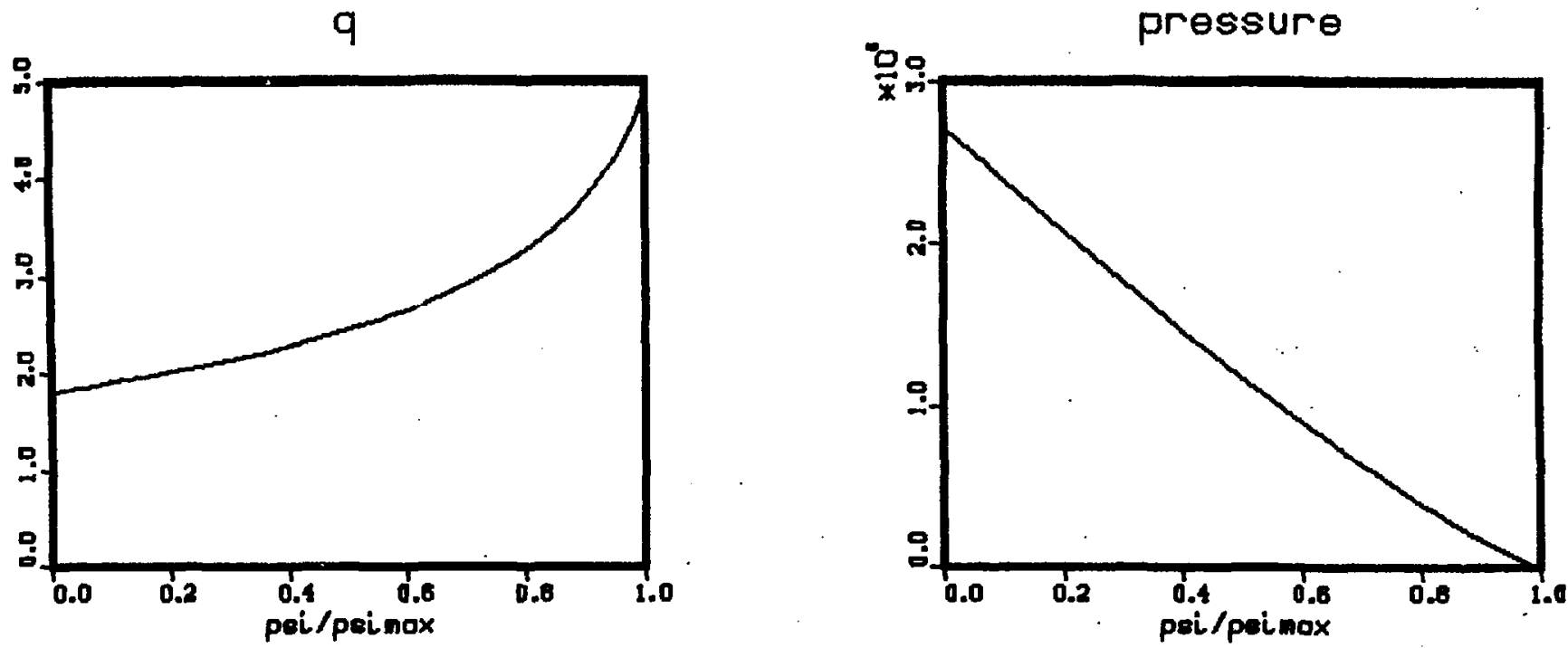

$i$ enclosed

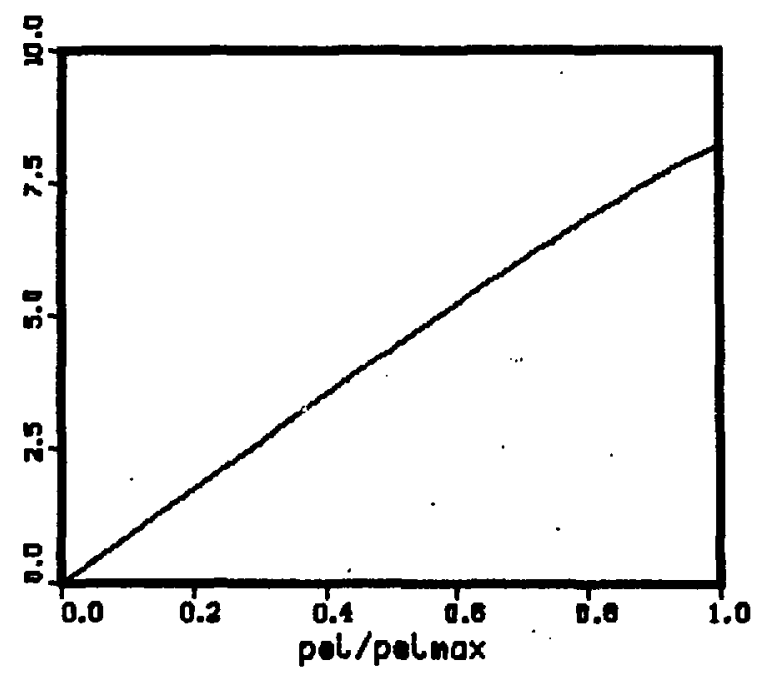

$\checkmark$ prime

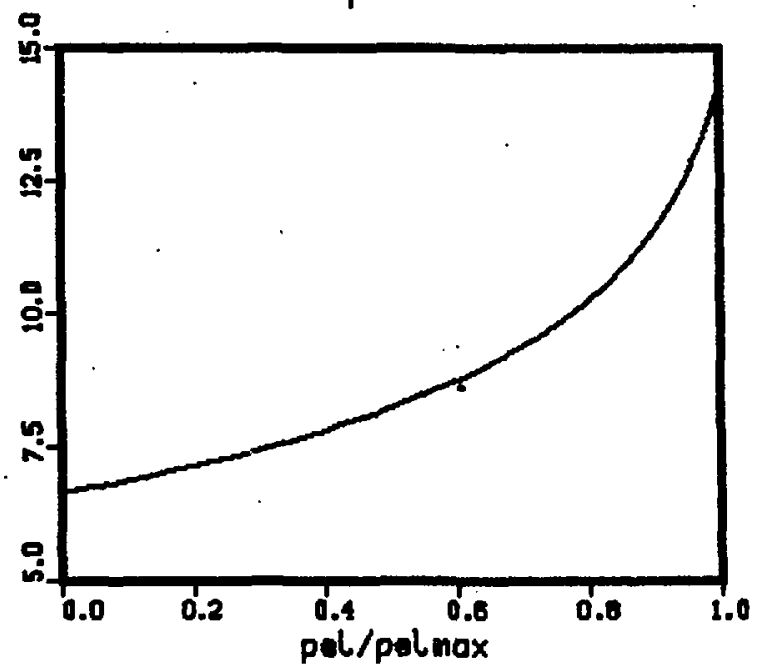

Figure 4. Same equilibrium as in Figure 3. 


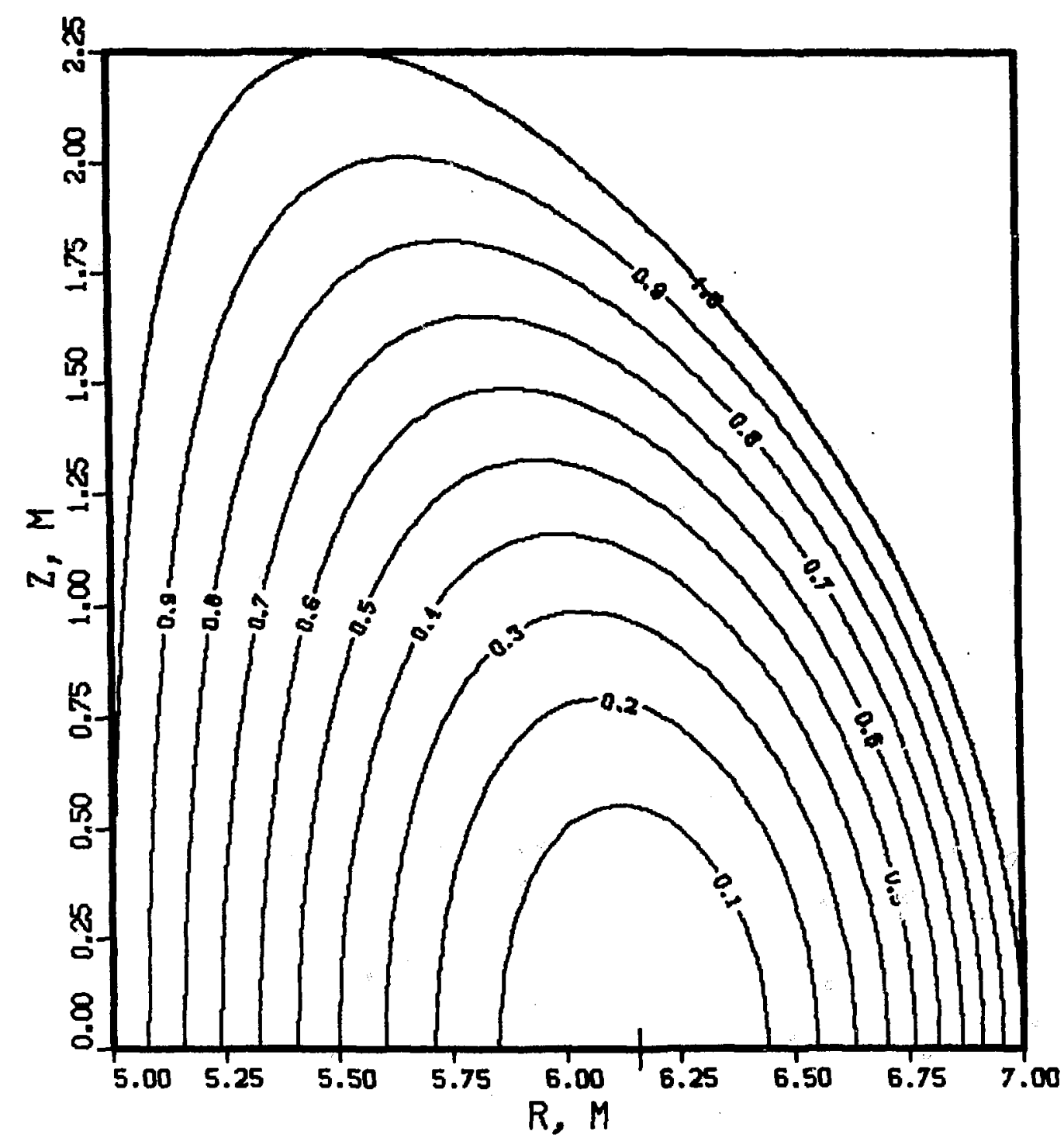

Figure 5. Poloidal flux contours for reference reactor. 


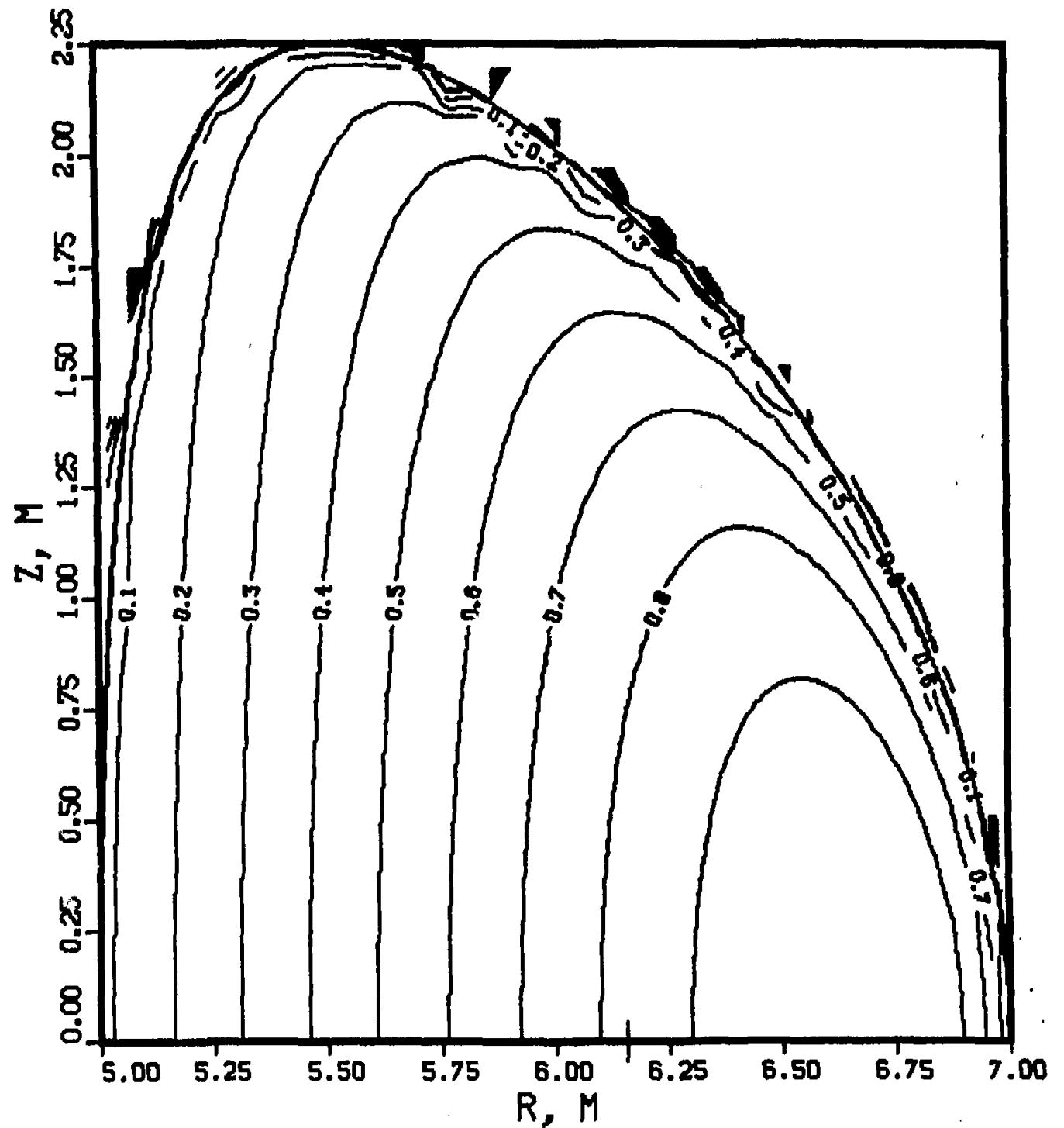

Figure 6. Contours of constant toroidal current density for reference reactor. 


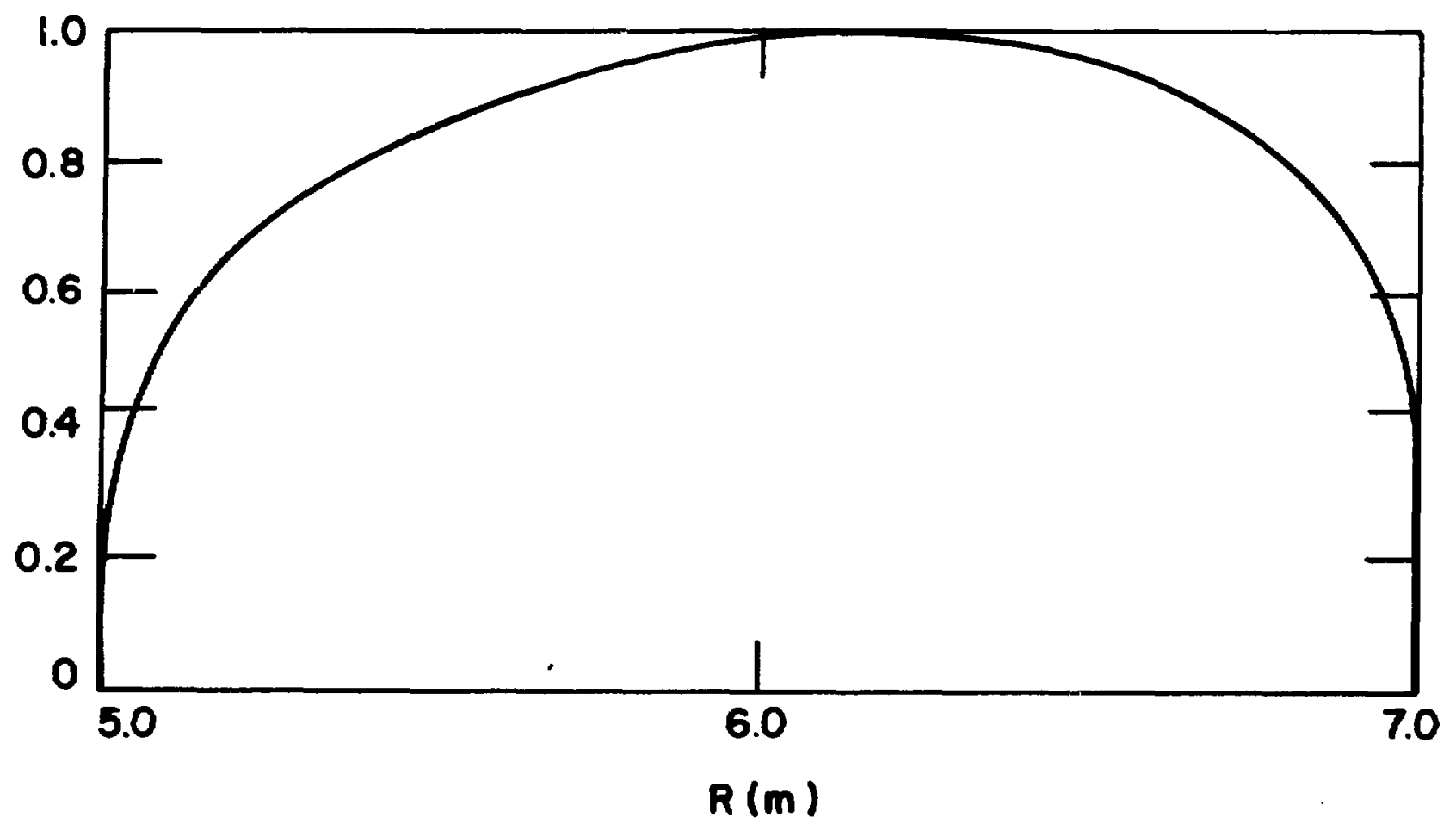

Figure 7. Normalized density for reference reactor: $n_{e} / n_{e o}=-0.3$.

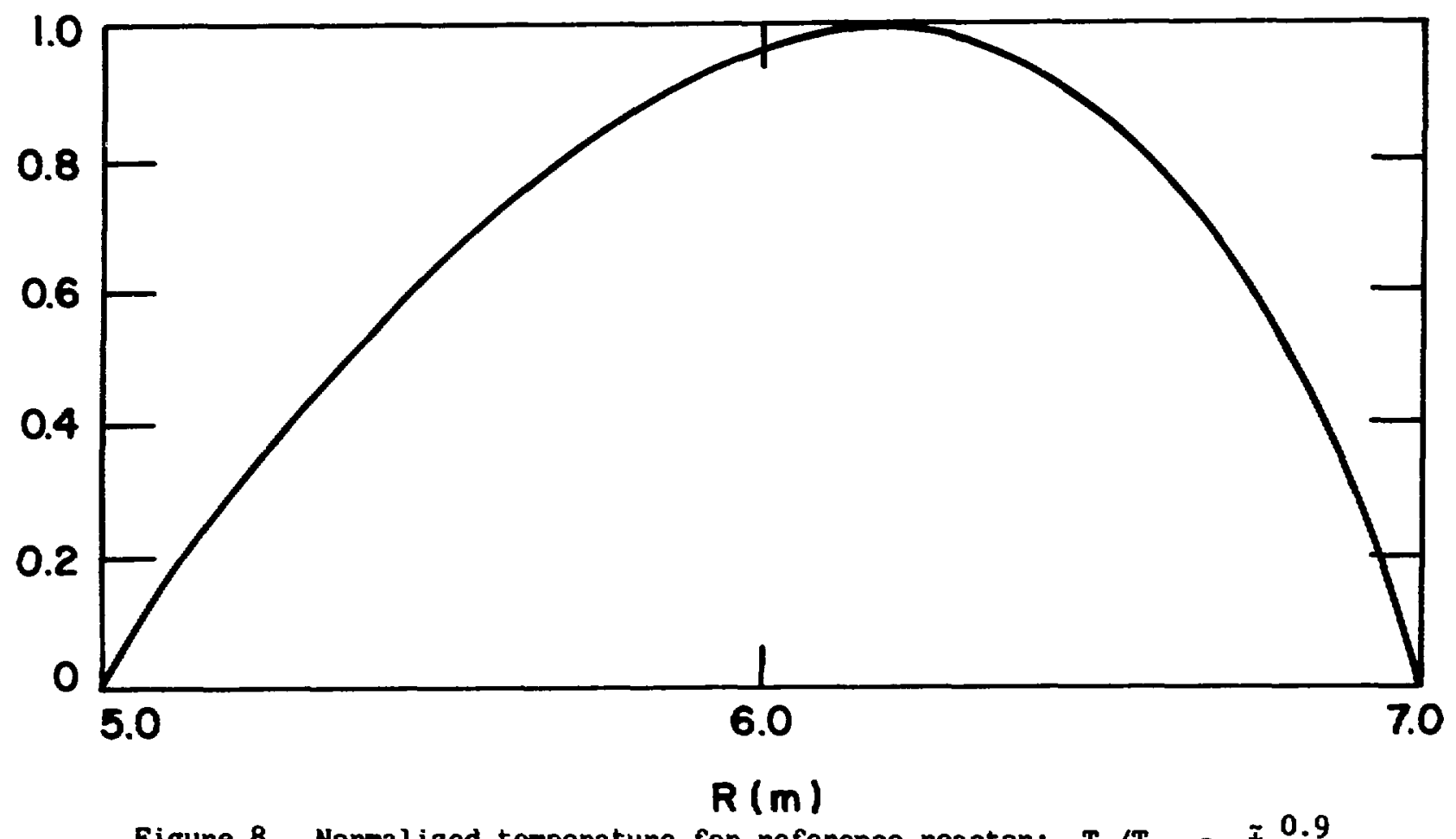

Eigure 8. Normalized temperature for reference reactor: $T_{e} / T_{e o}=\tilde{0.9}$. 

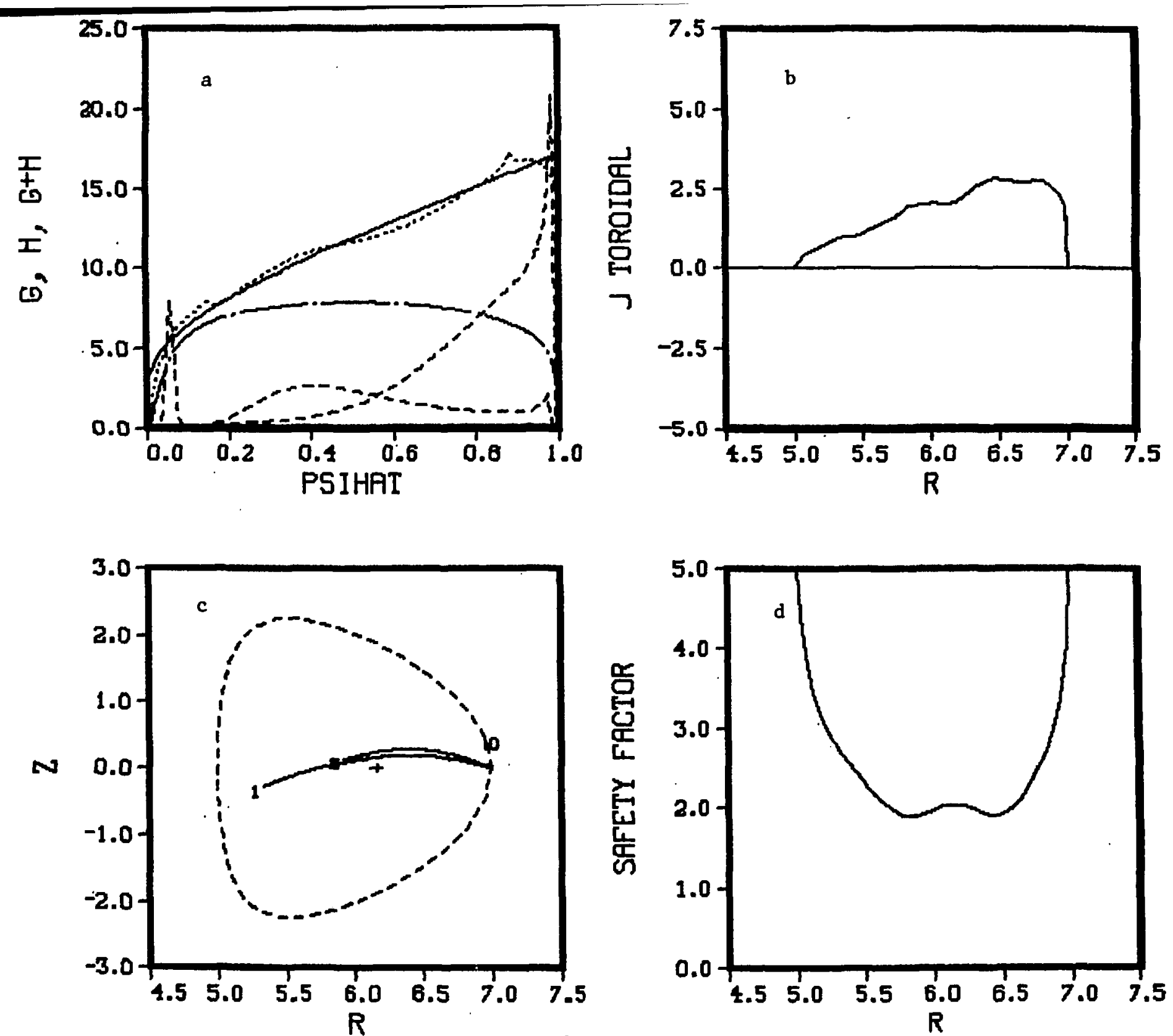

Figure 9

Equilibrium with fast-wave seed current and bootstrap contribution: a) chain dashed curve is $H$, dashed is wave-driven $G$ ( 3 rays), dotted is $G+H$, and solid is target $\left\langle J_{\|} B\right\rangle$ to be reproduced; $\left.\left.b\right) j_{t}(R, 0){ }_{1}, c\right)$ ray 
Internal
H. Attaya
C. Baker
M. Billone
J. Brooks
Y. Cha
O. Chopra
R. Clemmer
D. Ehst
K. Evans
P. Finn
Y. Gohar
L. Greenwood
D. Gruen
A. Hassanein
T. Hua
A. Hull
C. Johnson
A. Krauss
Y. Liu
B. Loomis
S. Majumdar
R. Mattas
B. Picologlou
K. Porges

C. Reed

D. Smith

H. Stevens

D. Sze

L. Turner

T. Yule

FPP Files (35)

ANL Contract File

ANL Library

ANL Patent Dept.

TrS Files (3)

\section{External:}

DOE-OSTI, for distribution per UC-420 (37)

Manager, Chicago Operations Office

D. Batchelor, Oak Ridge National Laboratory

S. Bernabei, Princeton Plasma Physics Laboratory

P. Bonoli, Massachusetts Institute of Technology

A. Boozer, College of William and Mary

L. Bromberg, Massachusetts Institute of Technology

J. Callen, University of Wisconsin, Madison

V. Chan, General Atomics

J. Connor, Culham Laboratory, U.K.

J. Cordey, JET Joint Undertaking, U.K.

M. Cox, Culham Laboratory, U.K.

R. Dory, Oak Ridge National Laboratory

F. Engelmann, Max-Planck-Institut fur Plasmaphysik, FRG

M. Fenstermacher, Lawrence Livermore National Laboratory

N. Fisch, Princeton Plasma Physics Laboratory

N. Fujisawa, Japan Atomic Energy Research Institute, JAPAN

J. Galombos, Fusion Engineering Design Center/ORNL

C. Gormezano, JET Joint Undertaking, U.K.

R. Hancox, Culham Laboratory, U.K.

F. Hinton, General Atomics

S. Hirshman, Oak Ridge National Laboratory

M. -Y. Hsiao, Penn State University

D. Ignat, Princeton Plasma Physics Laboratory

C.F.F. Karney, Princeton Plasma Physics Laboratory

G. Logan, Lawrence Livermore National Laboratory

S. Luckhardt, Massachusetts Institute of Technology

E. Mazzucato, Princeton Plasma Physics Laboratory

K. Miyamoto, University of Tokyo, Japan

D. Moreau, JET Joint Undertaking, U.K.

K. Okano, Toshiba Corporation, Japan

M. Ono, Princeton Plasma Physics Laboratory

A. Opdenaker, Office of Fusion Energy, U.S. Department of Energy 
V. Parail, I.V. Kurchatov Institute of Atomic Energy, USSR

J. Perkins, Lawrence Livermore National Laboratory

P. Politzer, General Atomics

M. Porkolab, Massachusetts Institute of Technology

D. Post, Princeton Plasma Physics Laboratory

R. Prater, General Atomics

P. Rutherford, Princeton Plasma Physics Laboratory

J. Sheffield, Oak Ridge National Laboratory

Y. Shimomura, Japan Atomic Energy Research Institute, Japan

D. Sigmar, Massachusetts Institute of Technology

T. Simonen, General Atomics

W. Stacey, Georgia Institute of Technology

K. Ushigusa, Japan Atomic Energy Research Institute, Japan

V. Vdovin, Kurchatov Institute, USSR

J-G. Wegrowe, Max-Planck-Institut fur Plasmaphysik, FRG

J. Wesley, General Atomics

M. Zarnstorff, Princeton Plasma Physics Laboratory 